\title{
Letramento e modos de ser letrado: discutindo a base teórico-metodológica de um estudo
}

\author{
Cecília Goulart
}

Universidade Federal Fluminense, Programa de Pós-Graduação em Educação

\section{Introdução}

Estudos vêm revelando aspectos dos caminhos que crianças, jovens e adultos percorrem para tornarse alfabetizados, bem como conhecimentos que estão envolvidos nesses processos (Pacheco, 1997; Andrade, 2000; Rocha, 2000; Garcia, 2004; Brito, 2004). Vêm, do mesmo modo, contribuindo para a reflexão sobre novas possibilidades de ação pedagógica com a linguagem verbal, na perspectiva de repensarem-se metodologias de trabalho que favoreçam a formação de sujeitos criticamente letrados. Tal formação estaria intimamente relacionada à construção da autoria e da cidadania, na medida em que associamos essas con-

* Coordenadora do grupo de pesquisa de que participam as doutorandas Helenice Aparecida Bastos Rocha e Cláudia Cristina Andrade; as mestres Maria Elena Venero Ugarte, Inez Helena Muniz Garcia, Maria Inês Barreto Neto, Angela Coelho de Brito; a mestranda Vanêsa Vieira Silva de Medeiros; e a bolsista do Programa Institucional de Bolsas de Iniciação Científica (PIBIC) Alessandra Iguassú da Fonseca. dições à condição letrada, isto é, à inclusão e participação dos sujeitos no tecido social por meio da apropriação de diferentes discursividades da linguagem escrita. Nosso interesse de pesquisa concentra-se, portanto, no aprofundamento da compreensão de processos e fatores envolvidos na construção daquela condição letrada.

Na linha apontada, o objetivo deste artigo é discutir a base teórica organizada para investigar aspectos de como os modos de ser letrado se constituem no espaço familiar e no espaço educativo. A pesquisa referida foi realizada com crianças de 4 e 5 anos de uma creche universitária, e tem como fundamentação principal estudos da área da linguagem. Foram realizadas entrevistas com a família das crianças e com profissionais da creche, visitas a residências, gravações em vídeo de rodinhas e situações de brincadeiras, além de observações na creche e de materiais e objetos produzidos ou atravessados de algum modo pela escrita, com os quais as crianças interagiam. Esses dados, entretanto, não serão apresentados no presente artigo, posto que se prioriza uma discussão teórica. 


\section{A noção de letramento: pressupostos e implicações teórico-metodológicas relevantes para o estudo}

Partimos do princípio de que a constituição da linguagem escrita pela criança: faz parte do processo geral de constituição da linguagem (Abaurre, 1988); e se dá como um trabalho contínuo de elaboração cognitiva por meio da inserção no mundo da escrita pelas interações sociais orais da criança, considerando a significação que a escrita tem na sociedade. Lemos (1988, p. 10) é quem nos ajuda a compreender:

Na maioria das vezes, o acesso da criança a textos ou a objetos portadores de textos - e a situações em que textos são produzidos, é identificado com a posição do espectador. E ainda quando se diz que a criança participa dessas atividades ou manipula esses objetos, não fica claro como práticas discursivas orais, e, portanto, interpretáveis pela criança, permeiam essas atividades, e oferecem a ela lugares e modos de participação.

Assim, pensamos que no processo de aprendizagem da criança as duas modalidades de linguagem verbal dialogam continuamente na perspectiva do letramento.

Estudos que investigam a relação oral/escrito vêm apontando aspectos instigantes para refletirmos sobre o processo de letramento e a condição letrada. Olson e Astington (1990) discutem que o letramento vem sendo visto como um fator central, tanto na transformação conceitual do sujeito quanto na cultural, e defendem que o letramento afeta a cognição indiretamente: o letramento afeta a língua e a língua afeta o pensamento. Mais especificamente, o letramento afeta o pensamento por intermédio do desenvolvimento de meios para se falar sobre o texto.

Os autores elaboram uma extensa e cuidada revisão de estudos que tratam do tema, observando que todas as línguas possuem uma metalinguagem - recursos para a referência ao que está sendo dito e ao tipo de coisa dita. Na tradição letrada, o texto vem a ser identificado com o que foi transcrito, isto é, com as próprias palavras. Analisam as investigações de Scribner e Cole (1981) na aldeia africana Vai, e chegam a duas conclusões: o letramento deve ser interpretado como algo mais geral do que a competência para a escrita - nesse sentido, ser letrado é ser competente para participar de uma determinada forma de discurso, sabendo-se ou não ler e escrever; e a escolarização parece fornecer competência para falar sobre o falar, sobre questões, sobre respostas, isto é, a competência de uma metalinguagem. Concluem, com base também em trabalhos de outros autores, que as consequiências cognitivas do letramento estão ligadas ao envolvimento em uma cultura letrada, e não diretamente às habilidades de leitura e escrita. Os autores observaram, como esperado, que a competência na tarefa de uso de verbos ligados ao ato de pensar (por exemplo, inferir, refletir) aumenta significativamente com a idade. Sugerem que essa competência é alcançada por meio de longos anos de prática, lidando com textos, lendo-os, comentando-os, comparando-os, julgando-os, e que seria por intermédio dessa linguagem especializada que o letramento contribui para o pensamento.

A abordagem desenvolvida por esses autores parece muito interessante, por destacar o desenvolvimento pelos sujeitos de reflexões metalingüísticas, revendo textos, conteúdos e objetos - falando sobre eles, da relação entre eles, do ponto de vista conceitual. De alguma forma o estudo citado também antecipa e problematiza algumas questões que serão tratadas na próxima seção.

Parece-nos, então, que o processo de apropriação da língua escrita pela criança está relacionado a aprender a transitar pelas duas modalidades da linguagem verbal - oral e escrita -, ajustando-as às situações de uso socialmente relevantes. Esse trânsito deve afirmar e ampliar a experiência discursiva anterior da criança e todos os conhecimentos aí envolvidos, incluindo a experiência de tomar a própria linguagem, ou aspectos dela, como objeto. Com base em Halliday (1975, apud Lemos, 1977), que analisa questões referentes ao processo de aquisição da linguagem oral, supomos que a criança, no esforço de aprendizagem da língua 
escrita, faça uso dos conhecimentos e recursos de que dispõe, utilizando-se do que Halliday denomina "estratégias semióticas". Essas estratégias permitiriam à criança utilizar-se de um sistema pouco ou mal conhecido enquanto ainda o está construindo, e de desenvolvê-lo por meio desse uso.

Nossos trabalhos anteriores vêm considerando os estudos de alguns pesquisadores na perspectiva de conceituar o que é ser letrado (Soares, 1998; Kleiman, 1995; Tfouni, 1996; Terzi, 1997; Teale, 1992; entre outros). Em termos gerais, o letramento estaria relacionado ao conjunto de práticas sociais orais e escritas de uma sociedade e também, segundo Tfouni (1996), à construção da autoria.

O termo letramento vem-se mostrando pertinente para os estudos sobre o processo de ensino-aprendizagem da linguagem escrita, já que se observa no Brasil o termo alfabetização ainda muito relacionado a uma visão dessa aprendizagem como um processo de codificação/decodificação de sons em letras e vice-versa. Essa visão está de um modo geral ligada à suposição de que a linguagem escrita é a fala por escrito. Nesse sentido, os sistemas escritos teriam sido inventados para representar a fala. Os autores que defendem essa idéia, em geral, entendem também que "a história da escrita seja a evolução progressiva que culmina no alfabeto" (Olson, 1998, p. 93). Essa concepção da história da escrita tem sido considerada etnocêntrica por alguns autores (Coulmas, 1989; Defrancis, 1989, citado por Olson, 1998; Michalowski, 1994).

A escrita, segundo Michalowski (1994, p. 60), foi uma nova forma de comunicação que trouxe à tona uma nova semiótica e novas formas de discurso. Olson (1998) defende que a escrita não é uma transcrição do oral, mas a elaboração de um modelo conceitual para o discurso, por permitir detectar não só os elementos lingüísticos, mas também as estruturas lingüísticas em que esses elementos se inserem. Muitos estudos, em contrapartida, vêm investigando mudanças históricas da língua escrita (Morrison, 1995), o que nos leva a refletir sobre transformações históricas também nas atividades de ler e de escrever, assim como na de falar.
Essas questões têm-nos levado a problematizar a noção de letramento, problematizando, ao mesmo tempo, as práticas pedagógicas de trabalho com a linguagem na escola, especialmente as práticas de alfabetização, mas não somente. Pesquisas desenvolvidas por nós anteriormente também nos encaminharam para esse interesse. Como se poderia caracterizar um sujeito letrado? Há diferentes formas de ser letrado? Que agências, pessoas, instituições, objetos, histórias, definiriam condições de letramento? Como alfabetizar letrando, como nos provoca Soares (1998)?

Vem sendo observado que crianças cujas famílias são letradas e que participam de atos de leitura e escrita desde muito cedo, vendo familiares escrevendo e lendo, ouvindo histórias, chegam à escola conhecendo muitos dos usos e funções sociais da língua escrita. Participam do que Heath (1982, p. 50) denomina eventos de letramento: "eventos em que a linguagem escrita é essencial à natureza das interações e aos processos e estratégias interpretativas de seus participantes". Em contrapartida, as crianças oriundas de famílias pouco alfabetizadas, ou não-alfabetizadas, isto é, com pouca oportunidade de participação em eventos de letramento, ao chegarem à escola, em sua grande maioria, entendem que texto escrito é aquele que a escola lhes apresenta, geralmente, textos acartilhados. Pode iniciar-se assim um processo de expropriação, e não de apropriação da escrita, ou, melhor dizendo, de expropriação do mundo da escrita. Mas que mundo é esse? Segmentos sociais diferentes utilizam-se de modos diferentes da linguagem escrita? De que forma esses modos influenciam a inserção das pessoas na chamada sociedade letrada?

Teale (1992) realizou relevante pesquisa sobre as orientações de letramento de 24 crianças norteamericanas pertencentes a famílias de baixa renda, investigando a extensão e a natureza das experiências de letramento das crianças pré-escolares, em suas casas, por meio da análise de diferentes estruturas de participação e domínio de atividades. O autor observa, por intermédio das evidências encontradas, que todas as crianças em uma sociedade letrada têm numerosas experiências com a linguagem escrita antes 
de entrar na escola. Observa também que essas crianças vivenciam o letramento como um processo social. Enfatiza que determinadas atividades de letramento realizadas nos lares se mostram como conseqüências inevitáveis da participação e inserção em uma sociedade letrada. Destaca que a situação doméstica se constitui em um complexo de fatores econômicos, sociais, culturais e pessoais, e que, embora a situação econômica possa afetar as circunstâncias de letramento, isso não é uma regra. O autor observou instâncias entre as famílias de baixa renda que têm sido caracterizadas por autores como "altamente letradas". Outro fator a destacar nas ações domésticas de letramento é a alta significação que a interface com instituições sociais diversas revela (escola, trabalho, governo e igrejas, por exemplo).

Compreendendo que o letramento está relacionado à apropriação de conhecimentos que constituem a cultura chamada letrada, nossos estudos, realizados com alunos e professores de escolas públicas, levamnos a dimensionar o relevante papel que a escola tem, especialmente para as classes populares, na constituição de sujeitos letrados. Podemos entender tal relevância no sentido da participação crítica nas práticas sociais que envolvem a escrita, mas também no sentido de considerar o diálogo entre os conhecimentos da vida cotidiana, constitutivos de nossa identidade cultural primeira, com os conhecimentos de formas mais elaboradas de explicar aspectos da realidade.

A necessidade de ampliar o conceito de alfabetização, no intuito de projetar um processo crítico de aprendizagem da leitura e da escrita que vá além do conhecimento da escrita e da leitura de frases e textos simples, é um dos fatores que vêm determinando a discussão sobre a noção de letramento. A aprendizagem da escrita de um modo restrito não alteraria o estado ou a condição do indivíduo no que diz respeito a aspectos sociais, psíquicos, culturais, políticos, cognitivos, lingüísticos e até mesmo econômicos; do mesmo modo, não alteraria determinados grupos sociais, em relação a efeitos de natureza social, cultural, política, econômica e lingüística (Soares, 1998, p. 18) que a condição de letrado lhes poderia possibilitar. Dessa forma, torna-se relevante distinguir o acesso ao sistema de escrita e ao seu conhecimento, como tecnologia, do acesso ao mundo da escrita e dos conhecimentos aí implicados, isto é, à escrita como prática social, como um saber, no caso do letramento.

Soares (1998) apresenta muitos aspectos complexos da noção de letramento. Destacamos aqui apenas alguns que nos parecem mais problemáticos em relação ao eixo do presente estudo. Primeiramente, a dificuldade de conceituar letramento; em segundo lugar, a possibilidade de conceberem-se letramentos, no plural; e, em terceiro, como consequiência das duas questões anteriores, a falta de condições para definir critérios de avaliação ou estabelecer diferentes níveis de letramento. Três outras antigas perguntas circulam a temática em si e o nosso estudo, particularmente, nem sempre de modo explícito: Por que alfabetizar? Para que alfabetizar? E como alfabetizar? Outros autores nos provocam com diferentes reflexões.

Oliveira (1995, p. 158) discute alguns aspectos referentes às relações entre cultura e modos de pensamento, especialmente no que diz respeito à situação de grupos culturais "pouco letrados" integrados nas complexas sociedades contemporâneas, letradas. O estudo indica que não só a exclusão de uma relação sistemática com a escrita, com a escola e com a ciência dificulta o desenvolvimento de formas de pensamento "tipicamente letradas". Esses modos de pensar "ligam-se sempre, de alguma forma, a atividades que favoreçam a transcendência, pelo homem, das condições concretas de sua inserção no mundo".

Kleiman (1995), com base em Scribner e Cole (1981), define letramento como um conjunto de práticas sociais que usam a escrita, como sistema simbólico e como tecnologia, em contextos específicos, para objetivos específicos. A autora destaca o modelo ideológico de letramento, concebido por Street (1984), ao lado do modelo autônomo de letramento, enfatizando que todas as práticas de letramento são aspectos não apenas da cultura, mas também das estruturas de poder em uma sociedade.

A discussão que envolve a noção de letramento é, portanto, densa e complexa, atravessada pelo viés 
político-ideológico. Verificamos, então, a necessidade de ampliar essa discussão, por meio de contribuições teóricas da teoria da enunciação de Bakhtin (1988, 1992, 1998), principalmente no sentido precípuo de refletir sobre a participação dos espaços educativos na construção do processo de letramento.

\section{A contribuição dos estudos da linguagem para a compreensão da noção de letramento: a relevância do trabalho de Bakhtin}

Partindo do princípio de que constituir linguagem é constituir sistemas de referências do mundo (Franchi, 1992), e também de que a constituição do sujeito, da linguagem e do conhecimento está irremediavelmente interligada, a linguagem oral ganha relevância especial. Esses sistemas de referência são interpretações possíveis que grupos humanos organizam do mundo ou de aspectos do mundo, e podem/ devem ir-se tornando cada vez mais abrangentes. Ao mesmo tempo, existem interpretações diferentes para complexos de saberes semelhantes, sem que isso signifique que uma interpretação, ou um sistema de referências, possa ser a correta. Entretanto, pode-se falar de interpretações mais e menos valorizadas socialmente.

Os modos como as pessoas expressam suas vivências, crenças, sentimentos e desejos são suas formas subjetivas de apresentar seus conhecimentos e suas relações com o mundo. São, portanto, as interpretações possíveis no/do interior de seus universos referenciais culturalmente formados. A linguagem tem um papel fundador nesse processo, não só do ponto de vista da construção da singularidade dos sujeitos, mas também da construção das suas marcas de pertencimento a determinado(s) grupo(s).

Considerando, por um lado, a oralidade como canal capaz de garantir a identidade e a memória dos sujeitos sociais e, por outro, a escrita que se institui associada a determinados conteúdos referenciais, é preciso pensar de que forma é possível estabelecer uma relação dialética entre essas duas modalidades de linguagem, de tal maneira que uma não se sobreponha à outra, mas que uma contribua com a outra para que os conhecimentos e sentidos historicamente confrontados sejam entendidos criticamente.

Em estudo anterior, afirmamos que a inclusão e a participação em uma sociedade letrada passam por conhecimentos de ordem prática, filosófica, científica e artística, como também por gestos, hábitos, atitudes, procedimentos e estratégias que constituem valores sociais. Esses diferentes tipos de conhecimentos estão associados a práticas, instituições e agentes sociais. No estudo citado, ressalvamos que não consideramos que as pessoas vão despojar-se de seus conhecimentos/linguagens, constituídos no cotidiano de seus grupos sociais de origem, para adotar outros. Essas várias formas de abordar, de interpretar, de viver no mundo podem conviver e propiciar um "chão" para que novas formas de ação sejam viabilizadas. Um dos nossos desafios é conceber como isso se realiza ou pode ser realizado.

Os estudos de Bakhtin vêm mostrando-se relevantes para a nossa compreensão da tensão discursiva que existe em qualquer grupo, espaço social ou sociedade, e que pode ser explicada dependendo de onde nos posicionemos. No caso de nossa pesquisa, o propósito é compreender como teias discursivas caracterizam os modos como pessoas se letram. Pretendemos, então, com base em princípios e categorias do trabalho do autor, explorar uma formulação preliminar.

A teoria da enunciação de Bakhtin destaca a produção de linguagem na perspectiva da enunciação, ressaltando a natureza social da situação de produção de discursos. Nesse lugar, os feixes de sentidos constroem-se, dialogam e disputam espaço, instaurandose como signos ideológicos. O Outro, parte constitutiva da situação social de enunciação, atua de modo que o sujeito também seja parte constitutiva dessa organização, constituindo-se. O diálogo, então, é condição fundamental para que se conceba a linguagem. A verdadeira substância da língua é constituída pelo fenômeno social da interação verbal, realizada por 
intermédio da enunciação ou das enunciações (Bakhtin, 1988, p. 123). No movimento dos sujeitos nas infindáveis situações de enunciação, os signos, pelo seu caráter vivo, polissêmico e ideologicamente opaco, têm sua significação determinada pelos contextos em que são produzidos.

Esses feixes de significações que os signos comportam podem ser relacionados a compreensões diversas de facetas do mundo, tanto construídas na vida cotidiana, empiricamente, quanto na tradição de formação de áreas de conhecimento, como a religião, a ciência, a filosofia, a arte, conformando o que Bakhtin chamou de "dialética interna do signo". A noção de heteroglossia sintetiza essa concepção de que qualquer signo, qualquer enunciado, encontra o objeto a que se refere recoberto de sentidos construídos na história e na cultura, ideologizado, portanto, "por uma espécie de aura heteroglóssica (isto é, por uma densa e tensa camada de discursos)", nas palavras de Faraco (2003). A noção de heteroglossia, que entrelaçamos com a de letramento, então, organiza-se a partir desse centro organizador, que é povoado de muitas visões de mundo, muitas palavras, muitas histórias, de várias origens que, dialogicamente, se fundam no social: um social não-homogêneo, não-transparente, ideologicamente opaco, constituído de signos.

Para Bakhtin, as diferentes esferas sociais de conhecimento, como o são as áreas de conhecimento mencionadas no parágrafo anterior, entre outras, estão relacionadas à utilização da língua e constituemse como linguagens sociais. Isto é, cada esfera social de conhecimento se relaciona a uma discursividade, caracterizando um determinado modo de conhecer aspectos da realidade e de explicá-los. Além disso, cada esfera da atividade humana elabora tipos relativamente estáveis de enunciados, marcados pela linguagem social que a conforma, que se constituem em gêneros do discurso (Bakhtin, 1992). Os gêneros organizam os conhecimentos de determinadas maneiras, associadas às intenções e propósitos dos locutores. $\mathrm{O}$ gênero/enunciado reflete as condições específicas e as finalidades de cada uma das esferas por meio de três aspectos: o conteúdo temático; o estilo verbal, ligado à seleção operada nos recursos da língua; e, sobretudo pela construção composicional. Esse último aspecto estaria mais relacionado à formação de gêneros do discurso.

$\mathrm{O}$ autor atribui grande relevância teórica à distinção dos tipos de gêneros primário e secundário. Os gêneros do discurso primários relacionam-se aos espaços mais próximos das pessoas, à família, à casa, à vida cotidiana, principalmente; os gêneros do discurso secundários aparecem em circunstâncias mais complexas e relativamente mais evoluídas de comunicação cultural, principalmente associadas à escrita, diferentemente dos gêneros primários. É então em um emaranhado discursivo que se formam o discurso social e os discursos individuais.

De interesse ainda para o nosso estudo é o destaque que Bakhtin dá à ideologia do cotidiano. Esta ideologia estabelece uma relação dialética com outros sistemas ideológicos constituídos, que estamos concebendo, de um modo genérico, como as disciplinas, os campos do conhecimento: filosofia, ciência, arte, religião, entre outros. Desses sistemas, formados a partir da ideologia do cotidiano, essa ideologia recebe seu tom e, em contrapartida, permite-lhes uma avaliação crítica viva, por meio de uma situação social determinada. Quer dizer, a ideologia do cotidiano garante vida, concretude, significância aos sistemas constituídos.

Bakhtin (1992, p. 283) afirma que "a variedade dos gêneros do discurso pode revelar a variedade dos estratos e dos aspectos da personalidade individual". Entendemos, assim, que a variedade dos gêneros do discurso utilizada por uma pessoa possa revelar a sua variedade de conhecimentos (conhecimentos de várias esferas sociais) e aspectos de sua personalidade, em duas medidas: a) na medida em que os conhecimentos produzidos pelas diferentes classes e grupos sociais circulam na sociedade de um modo geral; e b) à medida que classes e grupos sociais diferentes atribuem valores diferentes aos signos ideologicamente constituídos e vivenciam as situações sociais de modos diferentes. O fenômeno do letramento está, na perspectiva que adotamos, associado a diferentes lin- 
guagens sociais e gêneros do discurso, caracterizando os grupos sociais, e mesmo cada pessoa, de modo diferente.

Na perspectiva do letramento, entendemos que a escola seja uma agência social importante para a socialização de gêneros do discurso secundários associados às linguagens sociais em que se fundam. Ou seja, a escola deve fazer um grande investimento no trabalho com gêneros secundários, em diálogo com os gêneros primários que marcam os sujeitos, que lhes dão identidade.

Nesse contexto, duas questões devem ser salientadas em relação aos estudos de Bakhtin. A primeira diz respeito ao modo como o autor encara o processo de formação dos gêneros do discurso. Segundo ele, os gêneros secundários absorvem e transmutam os gêneros primários ligados à comunicação verbal espontânea. Nessa transformação, os gêneros primários adquirem uma característica particular: perdem sua relação imediata com a realidade existente e com a realidade dos enunciados alheios. Esse movimento parece estar relacionado ao que vem sendo chamado por alguns autores de "pensamento descontextualizado" (Oliveira, 1995).

A segunda questão está relacionada à inter-relação dos gêneros primários e secundários, de um lado, e ao processo histórico de formação dos gêneros secundários, de outro. De acordo com Bakhtin, é essa inter-relação que esclarece a natureza do enunciado e o difícil problema da correlação entre línguas, ideologias e visões de mundo. Este parece ser um ponto nodal para a nossa compreensão de diferentes letramentos e de como se constituem discursivamente. Nesse aspecto, se tomarmos o estudo em que Hall (2002) analisa e discute a construção de identidades culturais, com base em vários autores, poderemos elaborar outra hipótese. Se as crianças, jovens e adultos mais distanciados das linguagens sociais/gêneros do discurso secundários - que são mais próximos da linguagem escrita, e produzidos por ela - se apropriam destes, podemos supor que de alguma forma são traduzidos por eles. O que queremos dizer com isso? Supomos que, para aquelas pessoas que se apropriam de visões do mundo de certa forma estrangeiras ao seu universo sócio-histórico de origem, tal apropriação se deve dar de modo diferente daquelas pessoas para quem tais visões de mundo fazem parte de seu universo cotidiano, desde a mais tenra idade. Podemos, igualmente, supor que o mesmo ocorra com as pessoas cuja oralidade é mais próxima aos gêneros do discurso secundários - seriam traduzidas por outras linguagens sociais, outras formas de conceber o mundo.

Sabendo que a maioria da população brasileira está afastada do contexto e de uma atuação sistemática com a linguagem escrita e de atividades por ela perpassadas, ao entrar no contexto do mundo letrado, marcado por gêneros do discurso secundários, principalmente na escola, pode viver um processo de tra$d u c ̧ a \tilde{o}$, de ser traduzida. Isto é, ao se apropriarem do discurso da escrita, essas pessoas são transportadas para universos de referências diferentes de seus universos socioculturais de origem, o que inclui conhecimentos intrinsecamente ligados a valores. Hall (2002) trabalha com a idéia de tradução no sentido da formação de culturas híbridas associadas ao processo de globalização.

De um outro modo, Bakhtin (1998, p. 156) trata do fenômeno da hibridização, ao apresentar três categorias básicas de criação do modelo da linguagem no romance: a) hibridização; b) inter-relação dialogizada das linguagens; c) diálogos puros. As duas primeiras categorias, brevemente apresentadas a seguir, parecem-nos bastante relevantes para abordar a constituição dos discursos. A hibridização seria a mistura de, no mínimo, duas linguagens sociais no interior de um único enunciado.

O autor afirma que uma hibridização involuntária, inconsciente, é uma das modalidades mais importantes da existência histórica e das transformações das linguagens, acrescentando:

[...] no fundo, a linguagem e as línguas se transformam historicamente por meio da hibridização, da mistura das diversas linguagens que coexistem no interior de um mesmo dialeto, de uma mesma língua nacional, de uma 
mesma ramificação, de um mesmo grupo de ramificações ou de vários, tanto no passado histórico das línguas, como no seu passado paleontológico, e é sempre o enunciado que serve de cratera para mistura. (Bakhtin, 1998, p. 156-157)

Consideramos que podemos conceber certo plurilingüismo na linguagem, na medida em que esta se constitui com as palavras de outros, desde a gênese. Como nos diz Bakhtin (idem, p. 147-148):

Esse processo de luta com a palavra de outrem e sua influência é imenso na história da formação da consciência individual. Uma palavra, uma voz que é nossa, mas nascida de outrem, ou dialogicamente estimulada por ele, mais cedo ou mais tarde começará a se livrar da palavra do outro. Este processo se complica com o fato de que diversas vozes alheias lutam pela sua influência sobre a consciência do indivíduo (da mesma maneira que lutam na realidade social ambiente).

Aí temos, dessa forma, uma base para compreendermos a hibridização de linguagens tanto na dimensão do processo de apropriação da linguagem, no interior de tradições sociais das classes e de grupos, quanto na dimensão da participação em espaços sociais, especialmente os educativos, com o trabalho referenciado por complexas linguagens sociais e gêneros do discurso secundários. Essa pode ser uma das chaves também para a compreensão das dificuldades que crianças, jovens e adultos pertencentes a determinados estratos sociais têm de entendimento de discursos produzidos por pessoas cujos processos de letramento são fortemente marcados por textos escritos de gêneros secundários, conforme dados anedóticos de professores, médicos, entre outros, assim como de pesquisas que apontam essas situações.

A título de ilustração, trazemos o relato de uma professora que, tendo escrito no quadro-negro um bilhete que incluía a frase "Amanhã não haverá aula", para que as crianças o copiassem e o levassem para os responsáveis, se surpreendeu com os alunos perguntando à hora da saída: "Amanhã tem aula, tia?", parecendo que a forma verbal "haverá", distante da oralidade, não possuía carga semântica suficiente para a compreensão das crianças.

A questão sugere-nos que não seja um problema estrito de conteúdo ou de aprendizagem de novo vocabulário, como tradicionalmente tem sido visto, mas da própria organização sintático-discursiva e entonacional dos enunciados, cujos fundamentos e valores estão em linguagens sociais das esferas sociais de conhecimento a que se conectam complexamente.

A perspectiva delineada anteriormente interliga a noção de letramento a um modo de conceber as discursividades da linguagem verbal e seu contexto sócio-histórico, que problematiza de modo agudo seu ensino-aprendizagem. Discutindo e interligando essas diretrizes teóricas, para avançar no estudo sobre letramento, precisamos pensar de modo mais radical na constituição do sujeito, com base nas suas experiências em diferentes práticas e eventos sociais em que é inscrito e se inscreve.

Estamos entendendo as orientações de letramento como espectros de conhecimentos (Rommetveit, 1985, p. 183-184) desenvolvidos pelos sujeitos nos seus grupos sociais, em relação com outros grupos e instituições sociais. Esse espectro está ligado à vida cotidiana e a outras esferas da vida social atravessadas pelas formas como a linguagem escrita as perpassa, de modo implícito ou explícito, de modo mais ou menos complexo.

A noção de heteroglossia é vista como básica para a compreensão da noção de letramento, no sentido de que o letramento está vinculado ao conjunto de linguagens sociais que identificam práticas sociais, com expressões orais e escritas, e relacionado a instituições e a gêneros de discurso que aí se produzem. Estaria, conseqüentemente, conectado de modo forte à formação dos diferentes campos de conhecimento. Assim, vivendo em sociedades letradas, tanto os sujeitos escolarizados quanto os não-escolarizados são afetados de alguma forma pelo fenômeno do letramento.

Podemos talvez reconhecer aqui o que Street (1984) propõe ao conceber o modelo ideológico de letramento em oposição ao modelo autônomo de le- 
tramento. No modelo ideológico, o autor ressalta a dimensão político-ideológica daquela noção. Em Soares (1998, p. 75), lemos a afirmação daquele autor de que "a verdadeira natureza do letramento são as formas que as práticas de leitura e escrita concretamente assumem em determinados contextos sociais, e isso depende fundamentalmente das instituições sociais que propõem e exigem essas práticas".

\section{Conclusões: um modo de compreender a noção de letramento fundamentado em estudos da linguagem}

A necessidade de conhecer melhor os processos de alfabetização/letramento das crianças justifica-se pelo papel constitutivo que a linguagem tem na criação dos sujeitos e, por isso, a importância de contínuas revisões nas práticas de trabalho com a linguagem na escola. Justifica-se, também, pela possibilidade de geração de subsídios para novas investigações na direção de uma teoria social da alfabetização e do letramento.

Unindo as noções de letramento, heteroglossia e hibridização, a condição letrada estaria associada à condição de, pela linguagem, ser interna de modo crítico aos conteúdos e linguagens sociais que, atravessados pela escrita, disputam o jogo do poder no espaço político das relações sociais. A heteroglossia está ligada à compreensão crítica dos sujeitos e seus outros que, compondo o espectro discursivo social, revelam diferenças e afastamentos, semelhanças e aproximações, tensões e conflitos. Os enunciados, servindo de cratera para a hibridização, como afirma Bakhtin, vão formando-se e renovando-se continuamente pela apropriação de palavras alheias, fundadas em linguagens sociais.

A condição letrada é pressuposta como intimamente relacionada tanto a discursos que se elaboram em diferentes instituições e em práticas sociais orais e escritas, quanto a muitos objetos, procedimentos, atitudes, como formas sociais de expressão, entre elas a expressão em língua escrita.
Na perspectiva teórica apresentada, a escola pode ser um espaço de abertura para outras vozes e dimensões do conhecimento, para ampliar o mundo social plural dos sujeitos com múltiplos modos de mostrar, apreender, discutir e conhecer discursividades e gêneros do discurso ligados a diferentes linguagens sociais. Seria aumentado dessa maneira o espectro fragmentário do conhecimento dos sujeitos, de uma forma nãohierarquizada e não-homogênea. Apropriando-se do modo como diversos fatos e conhecimentos foram incorporados à sociedade e colocando em circulação outros modos de incorporação de fatos e conhecimentos, pode-se contribuir para novas formas de tensão social, novas práticas discursivas, novas ordens do discurso.

A dinâmica social mostra-se então complexa e heterogênea de múltiplas perspectivas. Destacamos aqui, principalmente, a perspectiva cultural, que se expressa em diferentes áreas do conhecimento (filosófica, científica, lingüística, artística, de gênero, étnica, religiosa, entre outras), e a perspectiva de classes sociais, que se expressa pelos diferentes valores atribuídos por essas classes aos diferentes conhecimentos, agências, objetos, atividades, relações e atitudes sociais. As formas como hoje esses caminhos se cruzam, aproximando-se e afastando-se, ao mesmo tempo, geram necessidades cada vez mais urgentes de se continuar repensando, entre muitas outras questões, e no sentido deste estudo, a prática pedagógica discursiva, no interior da prática social, nas suas múltiplas dimensões.

Com base na discussão teórico-metodológica apresentada, observamos que a relação oralidade/escrita se constitui como fator relevante para o estudo da caracterização dos modos como a condição letrada se constitui no espaço familiar e no espaço educativo. Assim, destacamos a importância de atividades que: trabalhem diferentes linguagens sociais em que a inter-relação de gêneros do discurso primários e secundários seja vivenciada; envolvam situações em que a linguagem escrita seja a fonte das interações, constituindo-se como eventos de letramento; promovam a reflexão sobre a própria linguagem, no sentido do desenvolvimento de uma metalinguagem. 


\section{Referências bibliográficas}

ABAURRE, Maria Bernadete Marques. O que revelam os textos espontâneos sobre a representação que faz a criança do objeto escrito? In: KATO, Mary (Org.). A concepção da escrita pela criança. Campinas: Pontes, 1988.

ANDRADE, Claudia Cristina. Leituras da mídia, leituras da escola: o toque mágico apaga ou transforma? 2000. Dissertação (Mestrado em Educação) - Faculdade de Educação, Universidade Federal Fluminense, Niterói, 2000.

BAKHTIN, Mikhail (Volochínov). Estética da criação verbal. São Paulo: Martins Fontes, 1992.

. Marxismo e filosofia da linguagem. São Paulo: Hucitec, 1988.

- Questões de literatura e de estética. A teoria do romance. São Paulo: Hucitec/UNESP, 1998.

BRITO, Angela Coelho de. O movimento discursivo nas rodinhas de crianças de 4 e 5 anos da creche UFF. 2004. Dissertação (Mestrado em Educação) - Faculdade de Educação, Universidade Federal Fluminense, Niterói, 2004.

COULMAS, Francis. The writing systems of the world. Oxford: Blackwell, 1989

DEFRANCIS, John. Visible speech: the diverse oneness of writing systems. Honolulu: University of Hawai Press, 1989.

FARACO, Carlos Alberto. Linguagem \& diálogo: as idéias lingüísticas do círculo de Bakhtin. Curitiba: Criar Edições, 2003.

FRANCHI, Carlos. Linguagem: atividade constitutiva. Cadernos de Estudos Lingüísticos, Campinas, n. 22, p. 9-39, 1992.

GARCIA, Inez Helena Muniz. Jovens e adultos em processo de alfabetização: voz e vida, revelações e expectativas. Dissertação (Mestrado em Educação) - Faculdade de Educação, Universidade Federal Fluminense, Niterói, 2004.

HALL, Stuart. A identidade cultural na pós-modernidade. Rio de Janeiro: DP\&A, 2002.

HALLIDAY, Michael Alexander Kirkwood. Learning how to mean. London: Edward Arnold, 1975.

HEATH, Shirley Brice. What no bedtime story means: narrative skills at home and school. Language in society, v. 1, n. 2, p. 46-79, 1982.

KLEIMAN, Angela. Modelos de letramento e as práticas de alfabetização na escola. In: (Org.). Os significados do letramento. Campinas: Mercado de Letras, 1995. p. 15-61.
LEMOS, Cláudia Guimarães. Redações no vestibular: algumas estratégias. Cadernos de Pesquisa, Fundação Carlos Chagas, n. 23, p. 61-71, dez. 1977.

. Prefácio. In: KATO, Mary. A. A concepção da escrita pela criança. Campinas: Pontes, 1988. p. 9-14.

MICHALOWSKI, Piotr. Writing and literacy in early states: A Mesopotamianist perspective. In: KELLER-COHEN, Deborah (Ed.). Literacy: interdisciplinary conversations. Cresskill, NJ: Hampton Press, 1994. p. 49-70.

MORRISON, Ken. Estabelecendo o texto: a institucionalização do conhecimento por meio das formas históricas e filosóficas de argumentação. In: BOTTÉRO Jean et al. Cultura, pensamento e escrita. São Paulo: Ática, 1995. p. 141-200.

OLIVEIRA, Marta Kohl de. Letramento, cultura e modalidades de pensamento. In: KLEIMAN, Angela (Org.). Os significados do letramento. Campinas: Mercado de Letras, 1995. p. 147-160. OLSON, David. A escrita e a mente. In: WERTSCH, James et al. (Orgs.). Estudos socioculturais da mente. Porto Alegre: Artmed, 1998. OLSON, David.; ASTINGTON, Janet Wilde. Talking about text: how literacy contributes to thought. Journal of Pragmatics, North Holland/Amsterdam, v. 14, n. 5, p. 705-721, 1990.

PACHECO, Cecilia Maria Goulart. Era uma vez os sete cabritinhos: a gênese do processo de produção de textos escritos. 1997. Tese (Doutorado em Educação) - Departamento de Letras, Pontifícia Universidade Católica do Rio de Janeiro, Rio de Janeiro, 1997.

ROCHA, Helenice Aparecida Bastos. Leituras da professora: suas vidas entre a casa e a escola. 2000. Dissertação (Mestrado em Educação) - Faculdade de Educação, Universidade Federal Fluminense, Niterói, 2000.

ROMMETVEIT, Ragnar. Language acquisition as increasing linguistic structuring of experience and symbolic behavior control. In: WERTSCH, James (Ed.). Culture, communication and cognition. Vygotskian perspectives. Cambridge: Cambridge University Press, 1985. p. 183-204.

SCRIBNER, Sylvia; COLE, Michael. The psychology of literacy. Cambridge, Mass.: Harvard University Press, 1981.

SOARES, Magda Becker. Letramento: um tema em três gêneros. Belo Horizonte: Autêntica, 1998.

STREET, Brian. Literacy in theory and practice. Cambridge: Cambridge University Press, 1984.

TEALE, William. Home background and young children's literacy development. In: TEALE, William; SULZBY, Elizabeth (Eds.). 
Emergent literacy. Writing and reading. Norwood, NJ: Ablex, 1992. p. $50-89$.

TERZI, Silvia Bueno. A construção da leitura. São Paulo: Pontes, Editora da UNICAMP, 1997.

TFOUNI, Leda Verdiani. Letramento e alfabetização. São Paulo: Cortez, 1996 (Coleção Questões da Nossa Época, v. 47).

CECÍLIA MARIA ALDIGUERI GOULART, doutora em letras pela Pontifícia Universidade Católica do Rio de Janeiro (PUCRio), é professora adjunta da Faculdade de Educação da Universidade Federal Fluminense (UFF), atuando no Programa de Pós-Graduação em Educação. Publicações recentes: A universalização do ensino fundamental, o papel político-social da escola e o desafio das novas políticas de alfabetização e letramento (In: SOUZA, Donaldo Bello de; FARIA, Lia Ciomar de. Desafios da educação municipal. Rio de Janeiro: DP\&A, 2003, v. 1, p. 259-277); Reinventando diálogos, vínculos, razões e sensibilidades (In: TEIXEIRA, Inês Assunção de Castro; LOPES, José de Souza Miguel. A escola vai ao cinema. Belo Horizonte: Autêntica, 2003, v. 1, p. 46-59); Uma abordagem bakhtiniana da noção de letramento: contribuições para a pesquisa e para a prática pedagógica (In: KRAMER, Sonia; JOBIM, Solange; FREITAS, Maria Teresa As- sunção de. Ciências humanas e pesquisa: leituras de Bakhtin. São Paulo: Cortez, 2003, v. 1, p. 95-112); com SELLES, Sandra Escovedo; RUMMERT, Sonia Maria. Dimensões e horizontes dos professores Gaudêncio Frigotto, Maria Ciavatta Pantoja Franco e Osmar Fávero no Programa de Pós-Graduação em Educação da UFF. (In: Dimensões e horizontes da educação no Brasil. Niterói: EdUFF, 2004, v. 1, p. 9-22); Educação infantil: “nós já somos leitores e produtores de textos" (Presença Pedagógica, Belo Horizonte, v. 11, n. 63, p. 16-21, 2005); Letramento e novas tecnologias: questões para a prática pedagógica (In: COSCARELLI, Carla Viana; RIBEIRO, Ana Elisa. Letramento digital: aspectos sociais e possibilidades pedagógicas. Belo Horizonte: Autêntica, 2005, v. 1, p. 41-58). Pesquisas atuais, apoiadas pelo CNPq e pela FAPERJ, respectivamente: "A noção de letramento como horizonte éticopolítico para o trabalho pedagógico: investigando diferentes modos de ser letrado"; e "A história da alfabetização do município de Niterói no século XX: em busca de determinantes e condicionantes políticos e pedagógicos". E-mail: cecilia@ism.com.br

Recebido em novembro de 2005

Aprovado em maio de 2006 
Resumos/Abstracts/Resumens

Cecília Goulart

Letramento e modos de ser letrado: discutindo a base teórico-

metodológica de um estudo

O estudo apresenta a discussão da base 
teórica de uma pesquisa realizada com dez crianças de 4 e 5 anos de uma creche universitária, cujo objetivo é investigar aspectos do processo de letramento dessas crianças, no espaço educativo e no espaço familiar. Considerou-se a participação das crianças em eventos de letramento, suas relações com objetos, atividades e procedimentos, produzidos ou atravessados pela cultura escrita e aspectos do movimento discursivo que ocorriam nas famílias e na creche. Discutem-se e entrelaçam-se estudos sobre a relação entre oralidade e escrita e estudos que, apresentando uma concepção social e dialógica da linguagem, nos levam a um modo de conceber a noção de letramento, com base, principalmente, nos conceitos bakhtinianos de linguagens sociais, gêneros do discurso, heteroglossia e hibridização. Tal discussão é básica na pesquisa para a definição de categorias analíticas que indiciem diferentes modos de ser letrado. Busca-se aprofundar a compreensão sobre o papel da escola e da família no processo de letramento. Palavras-chave: educação infantil; oralidade e escrita; letramento

Literacy and ways to be literate: a discussion of the theoreticalmethodological basis of a study The article discusses the theoretical basis of a research involving ten children between four and five years old from a university crèche. The aim is to investigate aspects of the process of literacy of these children both at school and at home. The children's participation in literacy events, their relations with objects, activities and behaviour associated with written culture, and discursive aspects of family and school movements were taken into consideration. Studies on the relation between oral and written language and studies that highlight a social and dialogical conception of language lead us to a conception of literacy based principally on Bakhtinian notions of social language, genres of discourse, heteroglossia and hybridization. Such a discussion is fundamental in the research for the definition of analytical categories evidencing different ways of being literate. It is intended to deepen understanding on both the role of the school and the family in the literacy process.

Key words: pre-school education; oral and written language; literacy

Letramiento y modos de ser letrado: discutiendo la base teóricametodológica de un estudio El estudio presenta la discusión de la base teórica de una pesquisa realizada con diez niños de 4 y 5 años de una guardería universitaria, cuyo objetivo es investigar aspectos del proceso de letramiento de estos niños en el espacio educativo y en el espacio familiar. Se consideró la participación de los niños en eventos de letramiento, sus relaciones con objetos, actividades y procedimientos, producidos $o$ atravesados por la cultura escrita y aspectos del movimiento discursivo que ocurrían en las familias y en la guardería. Se discuten y entrelazan estudios sobre la relación oral-escrita y estudios que, presentando una concepción social y dialoguista del lenguaje, nos llevan a un modo de concebir la noción de letramiento, con base, principalmente, en los conceptos bakhtinianos de lenguajes sociales, géneros del discurso, heteroglosa e hibridación. Tal discusión es básica en la pesquisa para la definición de categorías analíticas que muestren diferentes modos de ser letrado. Se busca profundar la comprensión sobre el papel de la escuela y de la familia en el proceso de letramiento.

Palabras claves: educación infantil; oral y escrita; letramiento 